\title{
The evolving role of endoscopic retrograde cholangiography before and after cholecystectomy
}

\author{
SC Ganguli MD, TM Pasha MD, BT Petersen MD
}

SC Ganguli, TM Pasha, BT Petersen. The evolving role of endoscopic retrograde cholangiography before and after cholecystectomy. Can J Gastroenterol 1998;12(3):187-191. Laparoscopy is the preferred approach for cholecystectomy; however the indications for pre- versus postoperative endoscopic retrograde cholangiography (ERC) are still evolving. The records of patients who had ERC performed one month before $(n=119)$ or after $(n=35)$ laparoscopic or open cholecystectomy from January 1990 to August 1992 (period 1), and 66 patients who had preoperative ERC from November 1995 to October 1996 (period 2) are reviewed. ERC indications, findings and outcomes were reviewed, and trends in the use of preoperative ERC from 1990 to 1996 were sought. Between periods 1 and 2 the yield of preoperative ERC increased from $36 \%$ to $58 \%$ ( $\mathrm{P}<0.01)$. The use of preoperative ERC for the indication of abnormal liver enzymes declined $(\mathrm{P}<0.05)$, while the yield increased $(25 \%$ versus $61 \%, \mathrm{P}<0.01$ ). Both the use of ERC and the yield remained stable for other indications. ERC was felt to have changed the surgical approach in $5 \%$ of patients. Primary indications for postoperative ERC $(n=35)$ included abnormal intraoperative cholangiography (43\%), liver function test abnormalities $(23 \%)$ and recurrence of preoperative symptoms (14\%); stones were found in $60 \%, 50 \%$ and $20 \%$ of patients with these indications, respectively. Overall, $46 \%$ of postoperative studies revealed duct stones. The roles for pre- and postoperative ERC are changing and depend greatly on the relative laparoscopic and endoscopic expertise at a given institution.

Key Words: Cholecystectomy, Choledocholithiasis, Endoscopic retrograde cholangiography, Laparoscopy

\section{Évolution du rôle de la cholangiographie rétrograde endoscopique avant et après la cholécystectomie}

\begin{abstract}
RÉSUMÉ : La laparoscopie est l'approche privilégiée pour la cholécystectomie. Toutefois, les indications d'une cholangiographie rétrograde endoscopique (CRE) pré- versus postopératoire, continuent d'évoluer. On passe ici en revue les dossiers de patients qui ont subi une CRE un mois avant $(\mathrm{n}=119)$, ou après $(\mathrm{n}=35)$ une cholécystectomie laparoscopique ou ouverte entre janvier 1990 et août 1992 (période I) et 66 patients qui ont subi une CRE préopératoire entre novembre 1995 et octobre 1996 (période II). Les indications, les résultats et l'issue de la CRE sont passés en revue et on a dégagé les tendances quant à l'utilisation de la CRE préopératoire entre 1990 et 1996. Entre les périodes I et II, le rendement de la CRE préopératoire a augmenté de 36 à $58 \%(\mathrm{P}<0,01)$. Le recours à la CRE préopératoire pour l'indication anomalie des enzymes hépatiques a chuté $(\mathrm{P}<0,05)$, alors que le rendement a augmenté $(25 \%$ contre $61 \%$, $\mathrm{P}<0,01)$. L'emploi de la CRE et son rendement sont demeurés stables pour les autres indications. La CRE aurait changé l'approche chirurgicale chez $5 \%$ des patients. Les indications principales de la CRE postopératoire $(\mathrm{n}=35)$ ont été entre autre une cholangiographie per-opératoire anormale (43\%), des anomalies aux tests de fonction hépatique (23\%) et la récurrence de symptômes préopératoires (14\%). On a décelé la présence de calculs chez 60,50 et $20 \%$ des patients. De façon globale, $46 \%$ des examens postopératoires ont révélé la présence de calculs dans le canal biliaire. Les rôles de la CRE pré- et postopératoire évoluent et dépendent beaucoup de l'expertise laparoscopique et endoscopique relative des diverses institutions.
\end{abstract}

Departments of Gastroenterology and Internal Medicine, Mayo Clinic, Rochester, Minnesota, USA

Correspondence: Dr BT Petersen, W19-Gastroenterology, Mayo Clinic, 200 1st Street SW, Rochester, Minnesota 55905, USA.

Telephone 507-284-8714, fax 507-284-0538, e-mail petersen.bret@mayo.edu

Received for publication October 24, 1997. Accepted February 23, 1998 
$\mathrm{I}_{\mathrm{r}}^{\mathrm{n}}$ $n$ recent years, there have been great advances in the approach to the therapy of gallstones. Laparoscopic surgery has changed cholecystectomy from a relatively invasive operation with a recovery period of approximately six weeks to a minor operation with patient discharge on the same or the next day and the resumption of full activity shortly thereafter. The approach to choledocholithiasis has, however, become more varied. In the era of open cholecystectomy, the surgeon could palpate the common bile duct and proceed to common bile duct exploration (CBDE) if appropriate. Tactile detection of stones is no longer possible when the laparoscopic approach is used, and laparoscopic CBDE requires specialized expertise and equipment. It is not clear whether this technique will prove to be a feasible approach for all practitioners of laparoscopic surgery. Endoscopic retrograde cholangiography (ERC) with endoscopic sphincterotomy is the usual treatment offered for choledocholithiasis. The efficacy of ERC for the treatment of choledocholithiasis exceeds $90 \%$, and, if performed preoperatively, failure may prompt open cholecystectomy with CBDE. However, the indications for preoperative versus postoperative ERC and the application of intraoperative cholangiography (IOC) are still varied and evolving. This is evident in several recent studies of the role of preoperative ERC in laparoscopic cholecystectomy where the rate of performance of ERC has ranged from $5.0 \%$ to $30.0 \%(1-3)$.

Our aim was to investigate the indications for preoperative and postoperative ERC as well as their efficacies in predicting the occurrence of choledocholithiasis. We also sought to understand better the evolving and future role of ERC as it relates to an area of general surgery that has become primarily a laparoscopic practice.

\section{PATIENTS AND METHODS}

A computerized registry of all surgical procedures is maintained at the Mayo Clinic, Rochester, Minnesota. A search of this registry was designed to list all ERCs performed one month before or after laparoscopic or open cholecystectomy from January 1990 to August 1992 (period 1) and from November 1995 to October 1996 (period 2, during which only preoperative ERCs were examined). The clinical and computerized records were then reviewed retrospectively. $\mathrm{Pa}$ tients with conditions other than symptomatic cholelithiasis and/or choledocholithiasis suspected on the basis of preoperative testing were excluded (eg, mass in the head of the pancreas, known primary sclerosing cholangitis). Potential indications for preoperative or postoperative ERC were noted, including a history of jaundice, biliary colic, pancreatitis, cholecystitis or cholangitis; abnormal liver function tests (LFTs); abnormal biliary ultrasonography; findings at IOC; and others.

In patients with multiple indications for cholangiography (eg, choledocholithiasis and common bile duct dilation on ultrasonography and abnormal LFTs) a primary or most compelling indication was assigned based on the clinical data available; other indications were also noted. In unclear cases, the following hierarchy, in descending order, was es-
TABLE 1

Findings of preoperative endoscopic cholangiography associated with open and laparoscopic cholecystectomies

\begin{tabular}{lcccc}
\hline & $\begin{array}{c}\text { January } \mathbf{1 9 9 0} \text { to } \\
\text { August } 1992\end{array}$ & $\begin{array}{c}\text { November } \mathbf{1 9 9 5} \text { to } \\
\text { October } \mathbf{1 9 9 6}\end{array}$ \\
$\begin{array}{l}\text { Primary } \\
\text { indication }\end{array}$ & $\begin{array}{c}\text { Number of } \\
\text { ERCs (\%) }\end{array}$ & \% stones & $\begin{array}{c}\text { Number of } \\
\text { ERCs (\%) }\end{array}$ & \% stones \\
\hline Abnormal LFTs & $60(50)^{*}$ & $25^{* *}$ & $23(35)^{*}$ & $61^{* *}$ \\
US CDL & $22(18)^{\dagger}$ & $77^{\dagger}$ & $14(21)^{\dagger}$ & $86^{\dagger}$ \\
Pancreatitis & $19(16)$ & 47 & $10(15)$ & 20 \\
Cholangitis & $7(6)$ & 14 & $4(6)$ & 75 \\
Biliary colic & $2(2)$ & 0 & $3(4)$ & 67 \\
US Dil EHD & $2(2)$ & 50 & $4(6)$ & 75 \\
Cholecystitis & $1(1)$ & 0 & $2(3)$ & 0 \\
Other & $6(5)$ & 50 & $6(9)$ & 33 \\
All & $119(100)$ & $36^{* *}$ & $66(100)$ & $58^{* *}$ \\
\hline
\end{tabular}

${ }^{*} P<0.05 ;{ }^{* *} P<0.01 ;{ }^{+}$Not significant. CDL Choledocholithiasis; Dil EHD Dilated extrahepatic duct; ERC Endoscopic retrograde cholangiogram; LFTs Liver function tests; US Ultrasonography

tablished for primacy of indications: choledocholithiasis on ultrasonography $>$ active cholangitis $>$ active or history of clinical pancreatitis $>$ isolated abnormal LFTs $>$ dilated extrahepatic duct on ultrasound. ERC success, findings, outcome and complications were reviewed. Outcome of selective IOC was also noted. Whether the ERC findings and diagnostic or therapeutic success or failure altered the subsequent surgical plan was also assessed. For this consideration, ERC and subsequent laparoscopic cholecystectomy were the usual anticipated management.

Finally, the trends in use of preoperative ERC (before open or laparoscopic cholecystectomy) and IOC for January 1990 through October 1996 at the authors' institution were reviewed. It should be noted that the total numbers for open or laparoscopic cholecystectomy in this last part of the study are crude totals and thus include incidental cholecystectomies during laparotomies for other purposes.

The $\chi^{2}$ test was used for categorical variables, and Student's $t$ test was used for continuous variables.

\section{RESULTS}

Data were collected on 154 ERCs in 151 patients between January 1990 and August 1992 (first period). There were 89 females $(58 \%)$; the mean age of the group was 57.5 years (median 61, range three to 92 years). Seventy-seven per cent of ERCs were done preoperatively and $23 \%$ were done postoperatively. Two patients had both pre- and postoperative studies, while one had two preoperative ERCs. During the second period (November 1995 to October 1996), 66 preoperative ERCs were performed on 66 patients. This group included 39 females (59\%), with a mean age of 62.5 years (median 68, range 23 to 85 years).

The primary indications and findings of preoperative and postoperative ERC during these periods are summarized in Tables 1 and 2. Unless stated, the results and discussion refer to primary indications for ERCs only. The most common pri- 
TABLE 2

Findings of postoperative endoscopic cholangiography associated with open and laparoscopic cholecystectomies: January 1990 to August 1992

\begin{tabular}{lcc}
\hline Indication & $\begin{array}{c}\text { Number of } \\
\text { ERCs (\%) }\end{array}$ & \% stones \\
\hline $\begin{array}{l}\text { Intraoperative cholangiogram- } \\
\quad \text { choledocholithiasis }\end{array}$ & $15(43)$ & 60 \\
$\begin{array}{l}\text { Recurrence of preoperative } \\
\text { symptoms }\end{array}$ & $5(14)$ & 20 \\
Postoperative abdominal pain & $3(9)$ & 67 \\
Postoperative abnormal LFTs & $8(23)$ & 50 \\
$\begin{array}{l}\text { Bile leak suspected } \\
\text { Other }\end{array}$ & $3(9)$ & 0 \\
All & $1(3)$ & 0 \\
\hline
\end{tabular}

EHD Extrahepatic duct; ERC Endoscopic retrograde cholangiogram; LFT Liver function test

mary indications for preoperative ERCs during period 1 were abnormal LFTs (50\%), abnormal ultrasonography (20\%) and a history of biliary pancreatitis (16\%). Overall, a total of 90 preoperative patients ( $76 \%$ ) had abnormal LFTs. On average, these patients had total bilirubin elevated to three times that of normal, direct bilirubin six times that of normal, alkaline phosphatase twice that of normal and aspartate transaminase 10 times that of normal. The most common ultrasonography abnormality prompting preoperative ERC was the presence of choledocholithiasis, seen in 27 patients (23\%), including three with acute pancreatitis and two with acute cholangitis as the primary indications for ERC. Cholangitis was the indication for $6 \%$ of preoperative ERCs.

Most postoperative ERCs were for choledocholithiasis noted or suspected on IOC (15 patients, $43 \%$ of postoperative ERCs). Other indications for postoperative ERC were recurrence of preoperative symptoms in five patients $(14 \%)$, postoperative abdominal pain in three patients $(9 \%)$, abnormal LFTs in eight patients (23\%), suspected bile leak in three patients $(9 \%)$ and failed IOC in one patient with biliary colic (3\%). The mean interval between cholecystectomy and postoperative ERC was 6.2 days (median three days). This varied depending on the indications: the mean interval was 3.1 days for abnormal intraoperative or $T$-tube cholangiography (median one day), 5.7 days for postoperative abdominal pain, 9.5 days for postoperative LFT abnormalities and 10.0 days for recurrence of preoperative symptoms.

Overall, $40 \%$ of all period 1 ERCs revealed duct stones, with similar proportions between pre- and postoperative studies ( $36 \%$ versus $46 \%$, not significant), and between elective and acute studies (41\% versus $36 \%$, not significant). Fourteen $(12 \%)$ of the preoperative examinations showed evidence of recent passage of stones through the ampulla of Vater, as suggested by a very patulous or torn biliary os. When stones noted on ultrasonography were the primary indication for ERC they were confirmed in 17 of 22 patients (77\%, Table 1). Overall they were confirmed in 20 of $27 \mathrm{pa}$ tients $(74 \%)$. They were also found in $47 \%$ of patients with a
TABLE 3

Trends in laparoscopic cholecystectomy: 1990 to 1996

\begin{tabular}{lccc}
\hline Year & $\begin{array}{c}\text { Total laparoscopic } \\
\text { cholecystectomies }\end{array}$ & $\begin{array}{c}\text { Preoperative } \\
\text { ERCs (\%) }\end{array}$ & $\begin{array}{c}\text { Intraoperative } \\
\text { cholangiogram (\%) }\end{array}$ \\
\hline 1990 & 136 & $3(2.2)$ & $28(20.6)$ \\
1991 & 386 & $16(4.1)$ & $78(20.2)$ \\
1992 & 457 & $55(12.0)$ & $69(15.1)$ \\
1993 & 486 & $48(9.9)$ & $88(18.1)$ \\
1994 & 469 & $61(13.0)$ & $100(21.3)$ \\
1995 & 480 & $47(9.8)$ & $115(24.0)$ \\
$1996^{*}$ & 447 & $42(9.4)$ & $114(25.5)$ \\
\hline
\end{tabular}

*Up to October 31, 1996. ERC Endoscopic retrograde cholangiogram

TABLE 4

Trends in open cholecystectomy: 1990 to 1996

\begin{tabular}{lccc}
\hline Year & $\begin{array}{c}\text { Total open } \\
\text { cholecystectomies }\end{array}$ & $\begin{array}{c}\text { Preoperative } \\
\text { ERCs (\%) }\end{array}$ & $\begin{array}{c}\text { Intraoperative } \\
\text { cholangiogram (\%) }\end{array}$ \\
\hline 1990 & 662 & $15(2.3)$ & $260(39.3)$ \\
1991 & 530 & $19(3.6)$ & $112(21.1)$ \\
1992 & 474 & $16(3.4)$ & $47(9.9)$ \\
1993 & 428 & $13(3.0)$ & $22(5.1)$ \\
1994 & 431 & $19(4.4)$ & $30(7.0)$ \\
1995 & 404 & $11(2.7)$ & $11(2.7)$ \\
$1996 *$ & 327 & $10(3.1)$ & $12(3.7)$ \\
\hline
\end{tabular}

ERC Endoscopic retrograde cholangiogram. *Up to October 31, 1996

prior history of pancreatitis and $25 \%$ of patients with preoperative abnormal LFTs ( 15 of 60 patients). Preoperative total bilirubin and alkaline phosphatase values greater than twice normal, however, increased the yield of ERC to 50\% and $45 \%$ of cases, respectively. Ninety-five per cent of stones found on preoperative ERC were located in the extrahepatic biliary tree.

During the second observation period, abnormal LFTs were a less frequent indication for preoperative cholangiography ( $35 \%$ versus $50 \%, \mathrm{P}=0.025)$, while the other indications remained proportionally the same. The overall incidence of positive studies rose from $36 \%$ to $58 \%(\mathrm{P}=0.002$ ). The improved yield was most marked for the indication of abnormal LFTs $(25 \%$ versus $61 \%$ respectively, $\mathrm{P}<0.001$ ). This increase may be related to the modestly higher levels of aspartate transaminase ( 419 versus $305 \mathrm{U} / \mathrm{L}$, not significant) and total bilirubin ( 77 versus $67 \mu \mathrm{mol} / \mathrm{L}$, not significant) but not of alkaline phosphatase ( 523 versus $570 \mathrm{U} / \mathrm{L}$ ).

Analysis of trends since 1990 (Tables 3,4) revealed a gradual nonsignificant rise in the use of IOC during laparoscopic cholecystectomies (21\% to $26 \%$ ) with a decline in the frequency of preoperative ERCs (1992 to 1996, not significant). (Data from 1990 and 1991 were not included because of the learning curve for laparoscopic cholecystectomy). The use of open cholecystectomy fell progressively from 662 cases in 1990 to 327 cases in 1996. During this period there was also a marked drop in the performance of IOC 
from $39 \%$ to $4 \%$, while the performance of ERC before open cholecystectomy changed little.

Preoperative ERC was felt to have changed the surgical approach in six cases (5\%) during the first period. Two studies revealed an unsuspected tumour of the ampulla of Vater; in another, ERCP revealed chronic pancreatitis and a distal biliary stricture, prompting performance of a Roux-Y hepaticojejunostomy. The inability to remove stones in three patients prompted the use of an open procedure instead of a laparoscopic approach.

Postoperative ERCs during the first period (Table 2) demonstrated duct stones in 16 patients $(46 \%)$, two bile leaks $(6 \%)$, seven dilated bile ducts without current stones (20\%) and eleven normal studies (31\%). The indications most likely to be associated with duct stones were postoperative abdominal pain (two of three patients), choledocholithiasis demonstrated on intraoperative cholangiogram (nine of 15 patients) and postoperative abnormal LFTs (four of eight patients). Only one of five patients with recurrence of preoperative symptoms was found to have duct stones. Another two patients had ERC done for a suspected bile leak: one study was normal, and cannulation was unsuccessful in the other (subsequent laparotomy confirmed a bile leak).

The overall failure rate for diagnostic or therapeutic ERC in period 1 patients (January 1990 to August 1992) was 10\% (15 cases), including 11\% for preoperative studies (13 of 119 cases) and $6 \%$ for postoperative studies (two of 35 ). Eleven of the 13 preoperative failures were due to failure to image the common bile duct. This included two studies terminated because of ampullary intramural contrast injections and one patient with Billroth II anatomy and an unreachable papilla in whom an unresectable pancreatic malignancy was found at laparotomy. These studies were done at a time when needle knife sphincterotomy was uncommon. Two failed preoperative procedures were for multiple common bile duct stones that could not all be removed endoscopically. At laparotomy, one had a cholecystoduodenal fistula; the other underwent CBDE, after which several retained stones still required percutaneous extraction. The two failed postoperative ERCs included a failed cannulation and a failed stone extraction. This stone passed on follow-up T-tube cholangiography three weeks later.

Complications occurred in eight procedures (5\%). Postsphincterotomy bleeding occurred in three patients: one episode resolved spontaneously, one was treated endoscopically and one required surgery. Mild (two) or moderate (one) post-ERC pancreatitis occurred in three patients, none of whom underwent a sphincterotomy. The two cases of intramural contrast injection occurred without sequelae. No cases of procedure-related sepsis occurred.

\section{DISCUSSION}

Approximately three-quarters of period 1 studies were done preoperatively, a proportion similar to that reported in other series (4-6). Of these, abnormal LFTs were present in threequarters and were the primary indication in one-half of pa- tients; a history of pancreatitis was the prime indication for $16 \%$ of preoperative ERCs. These indications vary widely in the literature (7-10). While abnormal ultrasonography was the primary indication for only one-fifth of preoperative ERCs, a dilated extrahepatic duct or choledocholithiasis was present on ultrasonography in $60 \%$ of preoperative ERC patients. The importance of preoperative ultrasonography as the primary indications for ERC varies by definition in other studies. In one, which defined CBD dilation as greater than $1 \mathrm{~cm}$, abnormal ultrasonography was an indication in only $16 \%$ of cases (9), while in another it served as the primary indication in $52 \%$ of cases (10).

Studies of preoperative cholangiography report widely varying rates of choledocholithiasis, ranging from $25 \%$ to $64 \%(1,2,5,8,11,12)$; our yield of $36 \%$ for preoperative ERCs in the first period of our study fell in the middle of this range, while the yield of $58 \%$ in the second period was significantly improved $(\mathrm{P}=0.002)$. In our series the best predictor of choledocholithiasis was the prior identification of stones on ultrasonography. The utility of this finding is tempered by the poor sensitivity of ultrasound for duct stones. Ductal dilation was also fairly effective at predicting choledocholithiasis, consistent with several other large studies $(8,11)$.

The presence of choledocholithiasis in nearly half of patients with pancreatitis or a history of pancreatitis was higher than that reported in most of the literature (5). This is also, perhaps, related to definitions, because we included only patients with the clinical diagnosis of biliary pancreatitis, while others have included patients with hyperamylasemia. Using selective ERC, Hainsworth et al (8) found choledocholithiasis in $36 \%$ of patients with a history of pancreatitis. Another recent study that documented pancreatitis by a raised amylase level and abnormal ultrasonography found choledocholithiasis in $57 \%$ of patients (12), and a Hong Kong study showed common duct stones in 26 of 42 (62\%) patients with biliary pancreatitis (3). The acuity of evaluation following onset of pancreatitis probably influences these differences.

The most common indication for postoperative ERC was an abnormal intraoperative cholangiogram. Choledocholithiasis was subsequently identified in over half $(60 \%)$ of the studies done. This yield was markedly higher than all the preoperative indications for ERC except visualization of choledocholithiasis on ultrasonography and thus supports a shift away from preoperative ERC towards use of IOC for those indications with a lower yield of positive studies. Almost half of patients $(40 \%)$ with choledocholithiasis on IOC did not have the same findings on ERC, which implies stone passage or false positive studies in a significant proportion of patients. Improved intraoperative documentation with either videotaped fluoroscopy or the routine combination of fluoroscopy and hard copy filming may reduce the latter problem.

It is difficult to compare the number of preoperative ERCs in the open versus laparoscopic groups during the 1990-96 period. The crude rates for both groups include patients undergoing concurrent nonbiliary procedures. This is obviously more common with open procedures. Hence, we 
suspect that progressively fewer 'simple' procedures and a greater proportion of incidental cholecystectomies were being performed by the open route. In this setting, choledocholithiasis is extremely infrequent and IOC is rarely indicated. This may explain the marked fall in the performance of IOC during open cholecystectomies.

As anticipated there was a progressive evolution in the use of preoperative ERC from 1990 to 1996. Although ERCs continue to be performed in the same proportion of patients (averaging $10.8 \%$ of laparoscopic and $3.2 \%$ of open cholecystectomy patients), there was a significant increase in positive studies ( $36 \%$ to $58 \%, \mathrm{P}=0.002$ ). This could be due to a shift in the approach towards patients with abnormal LFTs. Whereas preoperative ERC was previously used for most of these patients, IOC tends to be used in patients with milder abnormalities of LFTs with preoperative imaging reserved for markedly raised aspartate transaminase or total bilirubin levels. This explanation is supported by a more than twofold rise in the yield of preoperative ERC for this indication (from $25 \%$ to $61 \%$ of studies, $\mathrm{P}<0.001$ ).

Postoperatively, four of six patients studied for abdominal pain had stones. In contrast, neither abnormal LFTs nor recurrence of presenting symptoms was very effective at predicting retained stones. However, very small numbers compromise the importance of this finding.

Failure rates of $10 \%$ or less for endoscopic detection and treatment of choledocholithiasis have been attested to in several series $(8,9)$. Our failure rate of $9.7 \%$ during the 1990-92 interval was due to failed duct imaging in $12 \mathrm{pa}-$ tients and failed duct clearance in three patients. Use of hydrophilic cannulating wires and needle knife sphincterotomy has markedly reduced this rate of failed access among patients with strong indications for ERCP.

In a recent series of 1050 patients who underwent laparoscopic cholecystectomy by a single surgeon, the use of preop-

\section{REFERENCES}

1. Bonatsos G, Leandros E, Polydorou A, et al. ERCP in association with laparoscopic cholecystectomy. A strategy to minimize the number of unnecessary ERCPs. Surg Endosc 1996;10:37-40.

2. Korman J, Cosgrove J, Furman M, Nathan I, Cohen J. The role of endoscopic retrograde cholangiopancreatography and cholangiography in the laparoscopic era. Ann Surg 1996;223:212-6.

3. Liu C, Lai E, Lo C, Chu KM, Fan ST, Wong J. Combined laparoscopic and endoscopic approach in patients with cholelithiasis and choledocholithiasis. Surgery 1996;119:534-7.

4. Newman L 3rd, Newman C, Baird DR, et al. An institutional review of the management of choledocholithiasis in 1616 patients undergoing laparoscopic cholecystectomy. Am Surg 1994;60:273-7.

5. Quershi A, Browne A, Leahy AL, et al. ERCP in the management of patients having laparoscopic cholecystectomy: re-appraising current indications. Ir J Med Sci 1993;162:510-2.

6. Vitale GC, Larson GM, Wieman TJ, Cheadle WG, Miller FB. The use of ERCP in the management of common bile duct stones in patients undergoing laparoscopic cholecystectomy. Surg Endosc 1993;7:9-11.

7. Schutte H, Yarmuch J, Latorre R, et al. Endoscopic bile duct stone removal prior to laparoscopic cholecystectomy. J Laparoendosc Surg 1994;4:191-7. erative ERC in high risk patients (ie, those with studies suggestive of pancreatitis or common bile duct stones) dropped from $60 \%$ in the earlier third of patients operated to $30 \%$ in the last third $(\mathrm{P}<0.05)$. The authors related this to the development of laparoscopic techniques for common bile duct manipulation and/or exploration (13). We noted a different trend, wherein an initial increase in the rate of preoperative ERCs was followed by a gentle decline. We attributed the increase to our surgeons' gradual inclusion of patients at higher risk for duct stones during their learning curve, leading to an appropriate increase in the rate of preoperative ERCs. Most recently, with the refinement of operative cholangiography and laparoscopic techniques for the removal of duct stones we have also seen a decline in the use of ERC preoperatively. This evolution is supported by a recent decision analysis that suggested that selective performance of ERC following laparoscopic cholecystectomy minimized the number of procedures performed, and the overall cost and morbidity of care. Selective preoperative ERC for likely duct stones may be a clinically equivalent strategy (14).

These data on the indications for cholangiography and their rates of associated choledocholithiasis should assist in the selection of patients for endoscopy. Our use of preoperative ERC clearly evolved during the periods studied, with an increase in positive studies largely due to an increase in the levels at which abnormal LFTs were used as an indication for ERC. The optimal use and timing of cholangiography thus hinges on both the relative risk of duct stones and on the relative skills of the surgeon and the endoscopist. When the likelihood of stones is very high most studies favour preoperative cholangiography. Lower likelihood of stones and sufficient operator skills should prompt deferral of cholangiography to laparoscopy with laparoscopic or subsequent endoscopic management of identified stones.

8. Hainsworth PJ, Rhodes M, Gompertz RH, Armstrong CP, Lennard TW. Imaging of the common bile duct in patients undergoing laparoscopic cholecystectomy. Gut 1994;35:991-5.

9. Widdison AL, Longstaff AJ, Armstrong CP. Combined laparoscopic and endoscopic treatment of gallstones and bile ducts stones: A prospective study. Br J Surg 1994;81:595-7.

10. Stain SC, Cohen H, Tsuishoysha M, Donovan AJ. Choledocholithiasis: endoscopic sphincterotomy or common bile duct exploration. Ann Surg 1991;213:627-33.

11. Cisek PL, Greaney GC. The role of endoscopic retrograde cholangiopancreatography with laparoscopic cholecystectomy in the management of choledocholithiasis. Am Surg 1994;60:772-6.

12. Rieger R, Wayand W. Yield of prospective, noninvasive evaluation of the common bile duct combined with selective ERCP/sphincterotomy in 1390 consecutive laparoscopic cholecystectomy patients. Gastrointest Endosc 1995;42:6-12.

13. Voyles CR, Sanders D, Hogan R. Common bile duct evaluation in the era of laparoscopic cholecystectomy: 1050 cases later. Ann Surg 1994:219:744-52.

14. Erickson RA, Carlson B. The role of endoscopic retrograde cholangiopancreatography in patients with laparoscopic cholecystectomies. Gastroenterology 1995;109:252-63. 


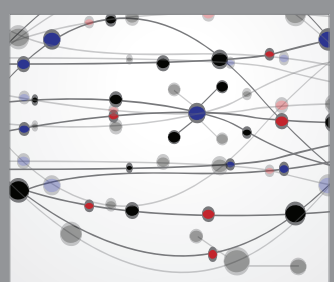

The Scientific World Journal
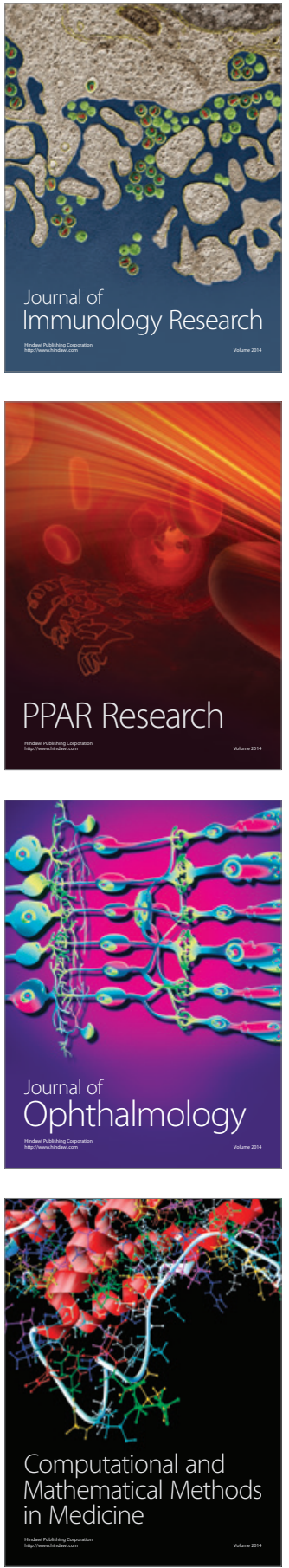

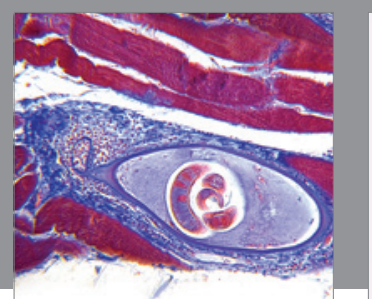

Gastroenterology Research and Practice

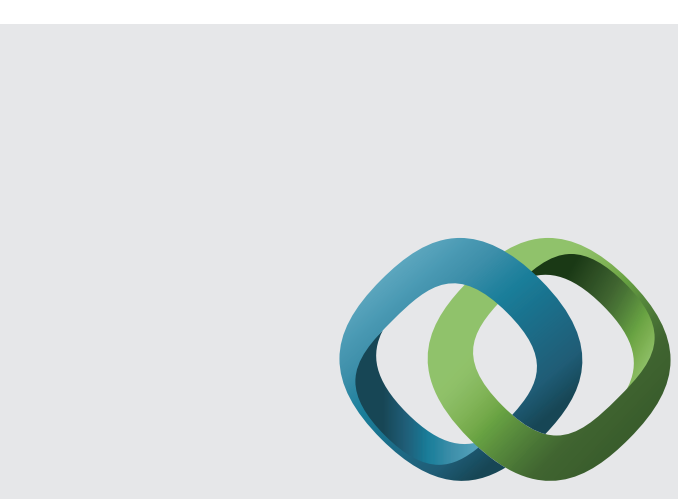

\section{Hindawi}

Submit your manuscripts at

http://www.hindawi.com
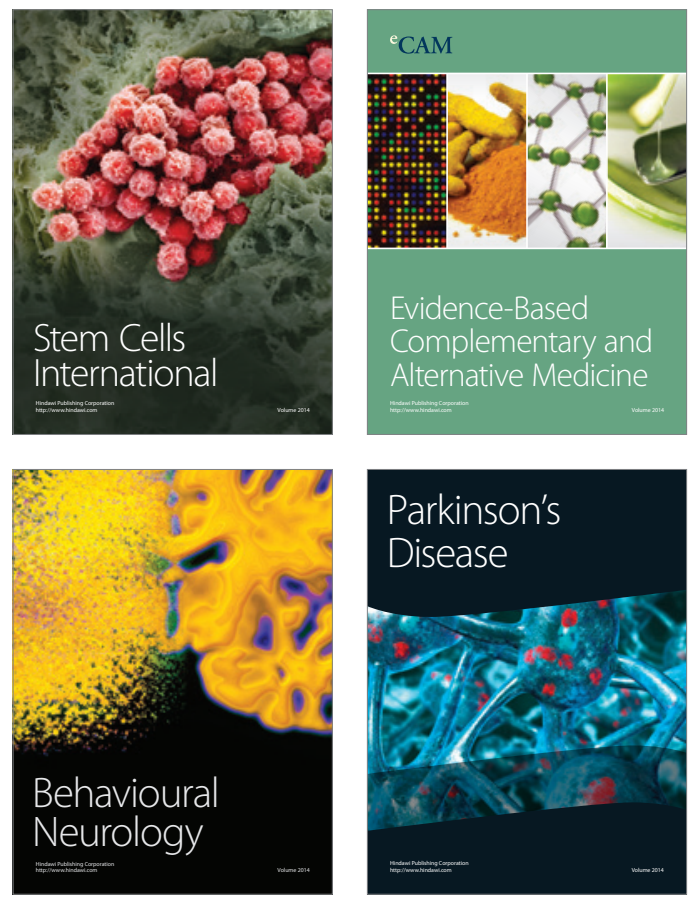
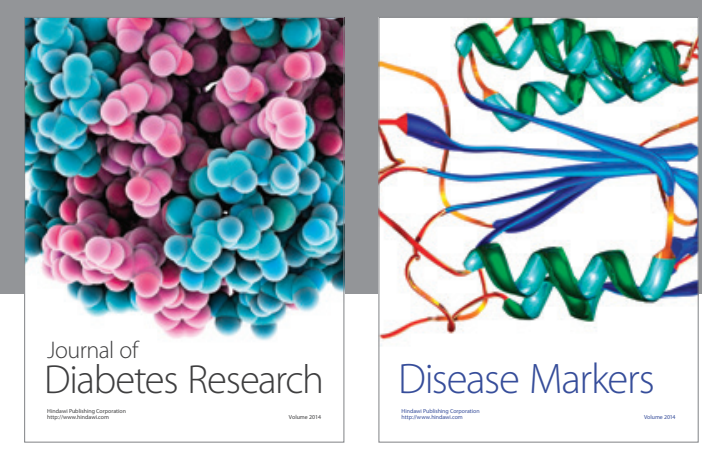

Disease Markers
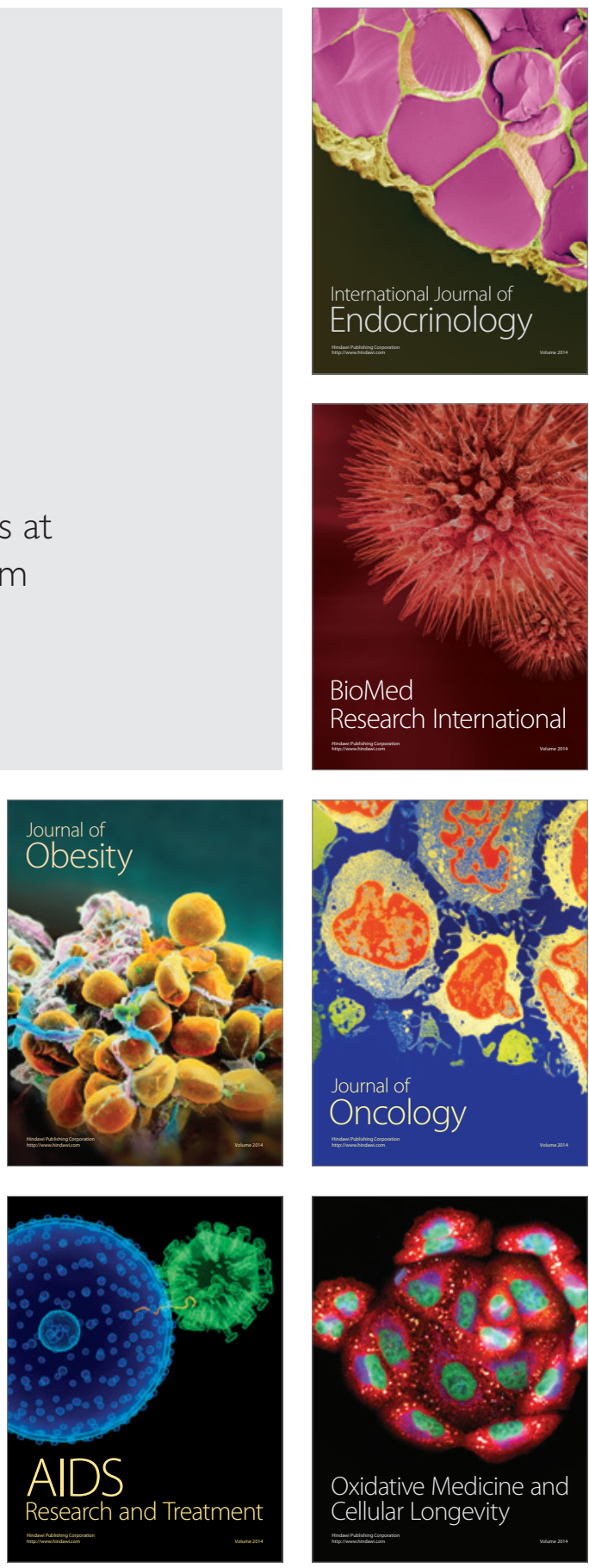